\title{
Erratum to: Molecular characterization and pathogenicity of fungal taxa associated with cherry leaf spot disease
}

Chethana KWT et al. 2020 - Erratum to: Molecular characterization and pathogenicity of fungal taxa associated with cherry leaf spot disease. Mycosphere 11(1), 2677, Doi 10.5943/mycosphere/11/1/19

Erratum to: Mycosphere 10(1): 490-530, Doi 10.5943/mycosphere/10/1/8

In this publication, there is an error in Figure 8 in the original article on page 515 . Figure 8 was published with an incorrect spore orientation microphotograph (8b). We therefore replace this figure with the correct figure below. We would like to apologize for any confusion or inconvenience this may have caused.

On Page 515, Figure 8 should be replaced with the following figure:
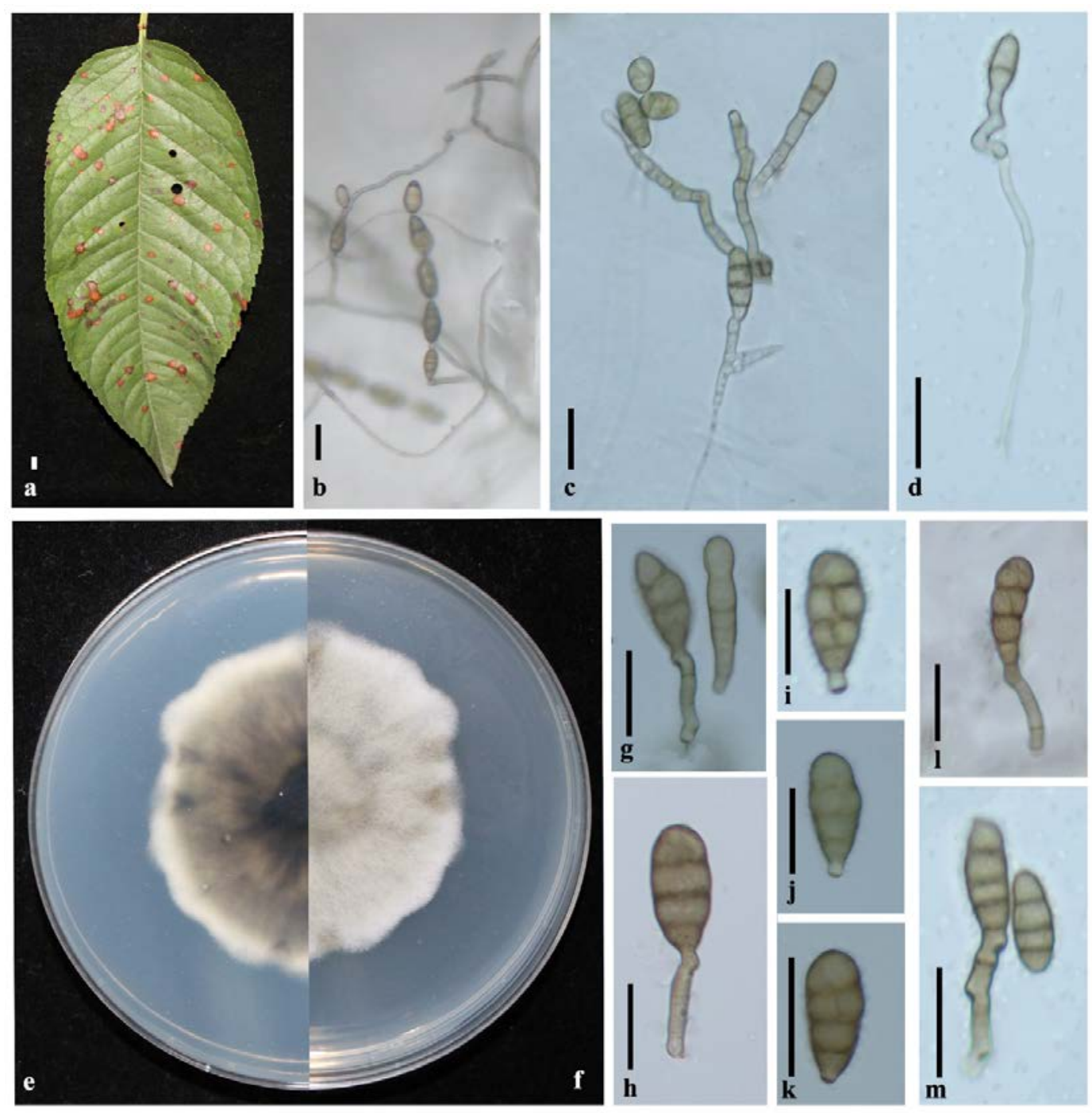